\title{
REFLEXIONES EN TORNO A LA GRACIA DIVINA DESDE EL NUEVO TESTAMENTO
}

\author{
REFLECTIONS ON THE DIVINE \\ GRACE FROM THE NEW TESTAMENT
}

Claudio Raúl Condori Cutimbo*

\begin{abstract}
RESUMEN
El presente ensayo reflexiona desde una perspectiva de la teología de la Gracia con el fin de hacer tomar conciencia sobre su importancia en la vida del cristiano y descubrir que Dios nos asiste desde siempre con su Gracia. Se aborda su comprensión en el Antiguo Testamento, donde no aparece de manera explícita el concepto de Gracia, pero donde existen elementos que nos permiten reconocerla como Gracia Divina, sobre todo el hecho de la Alianza que Dios hace con el pueblo elegido. En el Nuevo testamento se explicita tal comprensión desde la misma predicación $y$ acción de Jesús. Todo este camino nos lleva a reconocer que Dios desde su infinito amor nos sigue asistiendo con su Gracia, pero siempre respetando nuestra libertad, aún en los momentos que nos pareciera sentirlo ausente de nuestras vidas.
\end{abstract}

\section{PALABRAS CLAVE:}

Gracia, Elección, Alianza, Justificación, libertad, Aceptación.

\begin{abstract}
This essay reflects the Grace from a theology perspective in order to raise awareness about its importance in the Christian's life and discover that God is always helping us with his Grace. Its understanding is addressed in the Old Testament, where it does not appear explicitly the concept of Grace, but there are elements that allow us to recognize it as Divine Grace, especially the covenant that God established with his chosen people. In the New Testament this understanding is specified from the very preaching and action of Jesus. All this way leads us to recognize that God from his infinite love continues helping us with his Grace, but always respecting our freedom, even in moments when we feel that God seems to be absent from our lives.
\end{abstract}

\section{KEY WORDS:}

Grace, Election, Covenant, Justification, Liberty, Acceptation.

* Docente de la Universidad Femenina del Sagrado Corazón: rcondori@unife.edu.pe 


\section{INTRODUCCIÓN}

La presente reflexión intenta lograr un acercamiento y comprensión a esta realidad tan compleja y misteriosa que es la Gracia de Dios. Tomando en cuenta que a través de la Gracia se establecen las relaciones entre Dios y la humanidad, pues como reza el evangelio por la gracia hemos sido salvados, encontramos a través de ella el camino de la experiencia religiosa y el encuentro con Jesucristo.

La teología de la Gracia es un apartado de la reflexión teológica, que en nuestros tiempos no es tan actual para una inmensa mayoría ya que entre las varias razones se puede mencionar una tendencia al secularismo y al naturalismo de nuestra sociedad que nos hacen indiferentes y hasta contrarios a una dimensión tan importante para la comprensión integral de la persona.

Sin embargo la reflexión sobre la Gracia desde San Agustín y a lo largo de toda la historia de la teología ha sido un tema de muchas discusiones y sobretodo de estudio y de profundización.

El concepto de gracia en el nuevo testamento es amplio, puesto que bajo la palabra Gracia se encuentra la riqueza de la experiencia religiosa y de la fe cristiana como encuentro y relación entre el hombre y Dios. Desde los orígenes podemos descubrir que tanto en el griego como en el latín gracia reúne en sí varias realidades como pueden ser: benevolencia, amor, favor.

La Gracia es una acogida de la justicia de Dios por la fe en Cristo, es la que arranca al hombre del pecado que es contrario al amor de Dios. El hombre por la gracia purifica su corazón y descubre que ella es absolutamente necesaria, puesto que sin ella es imposible alcanzar la salvación, la vida eterna. La justificación implica el perdón de los pecados, la santificación y la renovación a una vida nueva.

Desde este discernimiento, sentimos la necesidad de la Gracia y podemos afirmar que todo cristiano siente que se encuentra bajo el misterio de la cruz de Cristo, que para los judíos, es decir, para los piadosos que quieren serlo por sus propias fuerzas, es un escándalo, y para los griegos, es decir para los hombres cultos a los que interesa la auto comprensión y auto fundamentación humana, es una necedad. «Mientras los judíos piden signos y los griegos buscan sabiduría, nosotros, por el contrario, predicamos un Cristo crucificado que resulta escándalo para judíos y necedad para gentiles» nos dirá San Pablo (1Cor 1,22s).

\section{El problema}

Antes de desarrollar el tema vemos la necesidad de preguntamos ¿Cómo aparece la situación espiritual del hombre de nuestro tiempo desde la perspectiva de la doctrina de la Gracia? Con su alejamiento de Dios, su "pérdida" en el mundo y su autonomía, el hombre se ha sentido inclinado en todos los tiempos, y muy especialmente en la época en que vivimos, a convertirse en punto de partida, medio y objetivo de sus afanes y búsquedas. Quiere conformar su vida y a sí mismo de una forma autónoma y libre. Lo que llegue a ser personalmente y lo que llegue a ser de su mundo quiere debérselo a sí mismo y no tener que agradecérselo a nadie.

Tanto más cuanto que el hombre en esta época de desarrollo vertiginoso de la ciencia y la tecnología está convencido que puede y debe configurarse y configurar 
su vida desde sí mismo. Todo, hasta las más hondas profundidades de su propio yo le parecen manipulables: nada está en sí, todo está ahí a su disposición y para él. Su pensamiento arranca del mundo experimental y se circunscribe a las realidades que es posible experimentar y controlar. Lo que en la época antigua y la edad media, expresaron metafísicamente desde una concepción creyente del mundo resulta sospechoso desde el renacimiento, por esa tendencia racionalista. Ya no se acomoda a aquella interioridad en la que únicamente es posible el encuentro con el Absoluto. El mundo que le rodea y el pensamiento objetivo, crítico y dominador de ese mundo -la razón- constituyen hasta tal punto las bases de su comprensión y actuación por lo que le resulta cada vez más extraña la relación con lo absoluto y totalmente trascendente. De algún modo el hombre se ha convertido en el Absoluto: el hombre es el segundo dios.

Frente a esta situación preocupante, la doctrina de la gracia parte de una interpretación aparentemente opuesta del mundo y de sí mismo. Esto podríamos verlo expresado en la breve frase de San Pablo cuando escribe «¿Qué tienes que no hayas recibido? "(1Cor 4,7), si lo has recibido, ¿por qué te glorías como si no lo hubieras recibido?» La actitud radical de independencia, propia del hombre, lo expresa siempre Pablo con el término "gloriarse". Más aun expresa Pablo con mayor profundidad este gloriarse en el don de Dios cuando asigna al hombre un «me ufanaré en mis debilidades a causa de mis flaquezas» (2Cor 11,30; 12, ss.), a fin de que la gracia de Dios resplandezca con mayor fuerza: Muy a gusto, pues, me gloriaré de mis flaquezas, para que en mí resida el poder de Cristo» (2Cor 12,9).

En el Sermón de la montaña, se exponen actitudes fundamentales a través de las bienaventuranzas: «Dichosos los pobres de espíritu, los que lloran, los mansos, los que sufren hambre y sed de justicia, los misericordiosos, los pacificadores, los que sufren persecución a causa de la justicia) (Mt 5,3-10; Lc 6,20 26). En estas se ponen de manifiesto unos modos humanos de conducta que sólo pueden llevarse a la práctica como fruto de la gracia de Dios (Lohse: 1985).

\section{Breve camino de la Gracia}

Para tener una visión panorámica de los aspectos más importantes del Antiguo Testamento, tomaremos a grandes rasgos los siguientes aspectos: 1. el orden histórico-salvífico; 2. el problema del pecado y de la santidad; y 3. el problema acerca de la consumación escatológica.

\subsection{Historia de la salvación}

El concepto y la imagen fundamental para la doctrina de la gracia en el Antiguo Testamento es la elección por parte de Dios; elección que afecta en primer lugar al individuo, pero visto siempre como miembro o cabeza de una familia o de una estirpe. Así se va poniendo en marcha, el gran acontecimiento de la vocación de Abraham. A través de su descendencia se convierte en el tronco de Israel, el pueblo elegido al que Dios dice más tarde: "Tú serás mi pueblo y yo seré tu Dios" (Dt 26,17s; Jer 7,23).

Esta idea de la elección encuentra su pleno desarrollo principalmente en Moisés y en la alianza con Dios. Si en Abraham y en sus descendientes era ante todo el individuo el llamado y tomando la alianza mosaica del monte Sinaí es el pueblo de Israel en cuanto tal quien ocupa el primer plano. Por ello, el pensamiento de elección está aquí vinculado a la organización de todo el pueblo israelita: 
al pueblo elegido pertenece ahora la alianza de Dios, junto con el culto y la Ley, con el sacerdocio y el ordenamiento político, económico y social. Todo el futuro del estado está determinado por Dios como teocracia(Mejía: 1975)

La idea de la alianza divina encuentra una nueva expresión durante la Monarquía, gracias al gran rey David. La guía divina anunciada a favor del patriarca, pasa ahora a David y a sus sucesores. Sobre esta idea del rey se levanta, especialmente a partir del destierro de Babilonia la nueva concepción del Mesías, que se convierte ahora en fiador de la elección y liberación del pueblo. Así como en tiempos antiguos fue Moisés quien, por encargo de Dios y como don divino a su pueblo, llevó a cabo el primer éxodo, la liberación y redención de la esclavitud de Egipto y dio a Israel la constitución de su realidad terrena como pueblo de Dios, en adelante la nueva redención del pueblo está relacionada al Mesías.

En esta idea histórico-salvífica de la elección y benevolencia divinas aparece lo que ya podemos llamar Gracia, en especial bajo el concepto de Hesed (benevolencia de Dios). Hesed es el amor de Dios y la benevolencia, que, como Dios de la alianza otorga a su pueblo aliado; amor y benevolencia con los que va unida su íntima y extraordinaria fidelidad, que se mantiene siempre, incluso cuando el pueblo es infiel.

El pensamiento de la elección divina no sólo cuenta para Abraham y sus descendientes sino que también está abierta a otros pueblos paganos, es una idea que ya aparece prefigurada en la alianza con Noé, que también se concibe como un pacto entre Dios y toda la humanidad. Auer. (1975).

\subsection{Pecado y santidad}

La mirada ahonda todavía más en el misterio del Dios benigno y en el misterio de su benevolencia cuando ésta no sólo sale al encuentro del hombre sin mérito alguno por parte de éste, sino que llega hasta el hombre en su indignidad y condición pecaminosa. Cuando Dios, en lugar de castigar con dureza al hombre, le otorga su benevolencia «según su gran misericordia (Sal 51,3; Is 54,7), Cuando la Biblia refiere que Dios entregó por segunda vez a Moisés las tablas de la Ley, agrega: «Pasó entonces Yahvéh por delante de Él y exclamó: iYahvéh es Yahvéh, Dios clemente y misericordioso, paciente y muy bondadoso y leal, que conserva la indulgencia hasta la milésima generación, que perdona la iniquidad, el crimen y el pecado; pero dejarlo no lo deja impune, antes castiga la iniquidad de los padres en los hijos y en los hijos de los hijos hasta la tercera y la cuarta generación!) (Ex 34,6ss). La confianza en Dios y el reconocimiento de la culpa, tal como aparece en los grandes salmos penitenciales muestran la fe profunda del hombre piadoso del Antiguo Testamento, como individuo, en este personalísimo e íntimo amor que late en Dios.

\subsection{Consumación escatológica}

El universal alcance de la benevolencia de Dios se pone de manifiesto cuando ya en las representaciones primeras del estado paradisíaco se describe al hombre cómo salido de las manos de Dios, libre de toda culpa y pecado, y cuando al final, sobre todo desde los profetas: Ezequiel, Jeremías, se alude cada vez más a la renovación escatológica del hombre y del mundo entero por obra de Yahvé Lona. (1998). Estas ideas son tanto más importantes cuanto que aparecen mucho antes de que en la época helenística 
encontremos en la piedad israelita una auténtica representación del más allá. «He aquí que llegan días - oráculo de Yahvé - en que pactaré con la casa de Israel y la casa de Judá una alianza nueva... pondré mi Ley en su interior y la escribiré en su corazón, y seré su Dios y ellos serán mi pueblo...perdonaré su culpa y no recordaré más sus pecados" (Jer. 31,31 - 34). "Y rociaré sobre vosotros agua pura y os purificaréis: de todas vuestras inmundicias y de todos vuestros ídolos os limpiaré. Y os daré un corazón nuevo, e infundiré en vuestro interior un espíritu renovado, y quitaré de vuestro cuerpo el corazón de piedra y os daré un corazón de carne. Infundiré mi espíritu en vuestro interior y haré que caminéis en mis preceptos y guardéis y practiquéis mis leyes... Vosotros seréis mi pueblo y yo seré vuestro Dios. Yo os libraré de todas vuestras inmundicias» (Ez. 36,25-28)

Es así que el mensaje de la Gracia de Dios en el Nuevo Testamento se relacionará con la doctrina del Antiguo Testamento, Sólo que cada uno de esos pensamientos tendrá una profundidad y alcance especial. En lugar de la idea de la alianza, pasa ahora al primer plano la idea del Reino de Dios, tal como lo habían desarrollado los profetas. Ahora ya no sólo aparece - con toda claridad la universalidad de la gracia y benevolencia de Dios, sino que se subraya el hecho de que Dios no llama precisamente a ese reino a los que serían los más dignos, sino más bien a quienes están más necesitados: los pecadores y los pobres. Especialmente en las parábolas de Jesús es donde aparecen esa misericordia gratuita de Dios (Mt 20,1.11: el Señor de la viña) y su bondad paterna (Lc 15,1132: el hijo pródigo). En la actitud de Jesús con los publicanos y los pecadores, se nos revela la benevolencia y gracia de Dios su Padre.

\section{La Gracia en el Nuevo Testamento}

En el Antiguo Testamento se reconocía ya a Dios como amor misericordioso y perdonador, sin embargo la revelación en su verdadera dimensión de ese amor se encuentra en el Nuevo Testamento. Es en efecto el hecho-Cristo lo que permite «comprender... cuál es la anchura y la longitud, la altura y la profundidad) (Ef. 3.18) del designio divino de salvación.

Ese designio va presentándose con creciente claridad en los inicios del nuevo testamento. Es así que los sinópticos, anuncian la buena noticia proclamada por Jesús con palabras y acciones, según la cual el reino de Dios ha irrumpido ya en su persona. Por su parte, los teólogos del Nuevo Testamento, Pablo y Juan, amplían y profundizan el mensaje sinóptico, enriqueciéndolo con aportaciones decisivas, a partir de las cuales el cristianismo va a erigir el concepto de Gracia en la categoría clave de su comprensión de la historia; categoría por lo demás absolutamente peculiar, toda vez que en el uso cristiano de la misma lo que con ella se denota no es algo, sino alguien: Jesucristo como manifestación escatológica del amor gratuito de Dios, que comunica a sus criaturas sanándolas y plenificándolas en una medida hasta entonces sólo oscuramente presentada por la revelación del Antiguo testamento Lona (1998).

Así brevemente presentaremos la comprensión de la Gracia, primeramente desde los sinópticos, luego abordar la comprensión desde la persona de Pablo.

\section{Los sinópticos}

Desde los sinópticos podemos realizar una reflexión desde tres aspectos fundamentales para enfrentar el problema de la gracia en el nuevo testamento y estos son: la predicación 
del reino, el seguimiento de Jesús, la paternidad de Dios.

Estos tres momentos están relacionados entre sí y anticipan ya el pensamiento teológico de Pablo y de Juan, que es la gratuidad de parte de Dios.

\subsection{El Reino en la predicación de Jesús}

«El tiempo se ha cumplido y el reino de Dios está cerca: conviértanse y crean en la buena nueva» (Mc 1,15). Con esta introducción comienza Jesús su misión pública. En él se manifiesta una llamada a la penitencia y a la conversión, motivadas por la proximidad del reino, una vez cumplido el plazo previsto por Dios, y se da por supuesta la capacidad humana de «cambiar de mente», ya reconocida en el Antiguo Testamento.

En esta introducción inicial, ni la exhortación a convertirse ni el anuncio del reino cercano son elementos originales porque ya los profetas del Antiguo Testamento insistieron incansablemente en la necesidad de la conversión; Juan el Bautista había proclamado la venida del hombre nuevo. La originalidad de Jesús respecto a tales precedentes coloca como fundamento que su anuncio tiene un carácter exclusivamente salvífico y silencia el carácter de castigo presente en los escritos del Antiguo Testamento, en efecto, ignora la alusión a «la ira inminente» de Mt 3,7-12, con la que Juan asociaba la proximidad del reino.

En la sinagoga de Nazaret Jesús reitera el mensaje de salvación y no de castigo, más aún reitera la dimensión que presenta Lc 4,22, lo que provoca en el auditorio una violenta reacción de rechazo y escándalo: «todos testimoniaban contra él», hasta el punto de querer despeñar al que osaba modificar el sentido de las palabras o anuncios del Antiguo Testamento (Lc 4,28-29).

Sobre la base de esta novedad principal de un anuncio exclusivo de salvación, las parábolas del reino destacan:

a. La absoluta gratuidad del mismo, que no depende en modo alguno del hombre y sus afanes, sino de la absoluta libertad y voluntad de Dios;

b. La urgencia de una decisión inaplazable por parte de sus oyentes que no pueden dejar de lado o dejar pasar la interpelación en ellas implicada.

c. La parábola del labrador paciente muestra cómo éste ni sabe ni puede hacer crecer la semilla. La enumeración minuciosa de las fases de ésta semilla tiende a preparar el clímax: «y de pronto... ha llegado la siega». Así es el reino: tan imperturbablemente seguro, tan independiente de las premuras y cuidados del hombre - que sólo puede poner a disposición su paciencia-, tan inesperado y generoso (Jeremias: 1979).

Por otro lado probablemente la parábola del labrador es la respuesta a la pretensión zelota de provocar o forzar la irrupción del reino: ¿por qué no actúa Jesús, expulsando de la comunidad a los pecadores, acaudillando la resistencia contra el invasor?

Jeremias (1979) en su comentario sobre la parábola de la siega, nos informa que responde a cómo el campesino no puede acelerar la hora de la siega, así los hombres no podemos acelerar la hora del reino, sino sólo aguardarlo.

También las parábolas del grano de mostaza y de la levadura (Mt 13,31-33) 
comparan el reino con el estadio final de los dos procesos en ellas aludidos (árbol, masa fermentada); lo que se busca es el contraste entre la pequeñez mínima del inicio y la magnitud desmesurada del término. El grano de mostaza «es ciertamente más pequeño que cualquier semilla» (v.32); la levadura se introduce en una enorme cantidad de harina, pero puede con toda y la hace fermentar. La grandeza del final está claramente exagerada en el caso de la mostaza; lo que ésta hace germinar es en realidad un arbusto (Mc 4,32), pero la versión de Mateo lo convierte en árbol frondoso: v. 32 (Jeremias: 1979)

Así ambas parábolas ilustran
el milagro de lo que deviene grandemente a partir de la nada o de lo supremamente pequeño. Lo que ocurre entre los estadios inicial y final no es de vital importancia como lo es el contraste que se quiere presentar. El minúsculo grupo de los que componen el movimiento de Jesús es el germen de la comunidad escatológica universal; he ahí «el misterio del reino de Dios», cuya revelación le es dada a los discípulos, mientras que «los que están fuera» no logran penetrar en el sentido auténtico de las parábolas (Mc 4,11-ss).

En relación con Mc 1, 15, otra de las parábolas del reino que apresuran la decisión: supuesto que Dios ha resuelto, gratuita y absolutamente libre, que éste es el momento y que la aurora de la salvación ya ilumina el mundo, el hombre ha de mostrarse a la altura de la hora y responder debidamente. Aparece aquí otro de los rasgos originales de la predicación de Jesús: él fue «el único judío antiguo, conocido por nosotros», que osó anunciar «que el tiempo nuevo de la salvación había comenzado ya».
La parábola de la higuera estéril (Lc 13,6-9) advierte a los oyentes de que están en el último plazo para la penitencia y la conversión: han pasado ya los «tres años» (v.7) previstos en principio. Si el dueño de la viña no procede de inmediato a talar la higuera es por pura condescendencia, que suspende una decisión ya tomada y ahora revocada misericordiosamente. Pero no se darán otras ampliaciones del plazo; este momento es, improrrogablemente, el último. Diríase que el señor se ha cargado de razón accediendo a la petición de clemencia del viñador: sólo cabe ya esperar que la higuera dé finalmente su fruto: de lo contrario, será cortada.

Así pues, y en resumen, aunque el reino sea pura Gracia y la iniciativa de su oferta concierne en exclusiva a Dios, el hombre es libre ante esa oferta; ha de asumir responsablemente lo que en ella se contiene, pudiendo, por tanto, rechazarla con igual responsabilidad. El «no habéis querido» de Mt 23,37 certifica esta libertad de la opción humana.

Por otra parte, afirma Ruiz de la Peña (1991) que la tensión dialéctica gratuidad de la oferta-libertad del hombre se acentúa por el hecho de que el polo gratuidad implica además la imposibilidad en que el hombre se encuentra de cobrar lo ofertado por propios méritos o de fabricarlo por propia virtud. «¿Quién se podrá salvar?», se preguntaban los discípulos. La respuesta es clara: «para los hombres, eso es imposible, más para Dios todo es posible» (Mt 19,25-26), pues Dios es dador de Gracia.

\subsection{El seguimiento de Jesús}

Se ha mencionado antes en el pasaje de Mc 4,11 ss.: sólo a los discípulos les es concedido penetrar en «los misterios del reino». Dicho más claramente: el 
seguimiento de Jesús es la premisa inexcusable de la consecución del reino. Tal premisa no es, por lo demás, algo que atañe a una élite de iniciados; es un requisito universalmente exigible. En Mc 8,34-38 se aplica «a la gente a la vez que a sus discípulos» lo que en Mt 16,24ss. Dice «a los discípulos»: «si alguno quiere venir en pos de mí..., sígame». La versión de Lucas (LC 9,23): «decía a todos» afirma de manera clara esta universalidad de la exigencia del seguimiento.

Debemos notar también que el seguimiento, ha de ser precedido por un llamamiento. Las tres variaciones sobre el tema Lc 9,57-62 son sumamente ilustrativas al respecto. El primer candidato a discípulo (v.57) es desalentado por Jesús (v.58); ha sido él mismo quien, sin haber sido llamado, le proponía seguirlo.

La respuesta que recibe le recuerda que el seguimiento es la cruz «si alguien quiere venir en pos de mí,...tome su cruz y sígame» y nadie puede desear la cruz por propia elección, nadie puede llamarse a sí mismo para ir en pos de Jesús, por ello cuando es Jesús quien llama, entonces ningún retraso es tolerable.

El segundo candidato le pide tiempo, no por razones frívolas o de poca monta, sino para cumplir con un deber filial que era a la vez una obligación legal («déjame ir primero a enterrar a mi padre»: v.59).

Jesús, casi brutalmente, le advierte que su llamada confiere al seguimiento una prioridad absoluta. Como señala un comentarista, «quizá ninguna sentencia de Jesús fue tan difícil de aceptar para sus oyentes) como ésta(Ruiz de la Peña: 1991).

El tercer candidato, al igual que el primero, entiende el seguimiento como efecto de la propia iniciativa. Pero además, al igual que el segundo, lo condiciona («te seguiré, Señor, pero déjame antes despedirme de los de mi casa»: vv.61-62). La reacción de Jesús es tajante: el seguimiento no tolera condiciones previas; quien las plantea con ciertas condiciones entonces «no es apto para el reino» (v.62).

La incondicionalidad y la prioridad absoluta del seguimiento se destacan también con suma eficacia en el episodio del joven rico (Mc 10, 17-22).

Debe notarse que lo que aquí está en cuestión no es cómo entrar a formar parte de un círculo selecto, sino algo mucho más elemental y que importa a todos; se trata de saber lo que hay que hacer «para tener en herencia la vida eterna» (v.17), es decir, pura y simplemente para salvarse.

Jesús articula su respuesta en dos tiempos. Ante todo, le recuerda al joven la doctrina común: hay que cumplir el decálogo. Pero luego le exige algo inédito, sin lo cual «falta una cosa»; el joven ha de despojarse previamente de todo y seguir a Jesús. Sin eso, el completo cumplimiento de la ley es aún deficiente. El despojamiento previo como requisito del seguimiento había sido ya demandado a los discípulos: «nosotros lo hemos dejado todo y te hemos seguido»; Mt 4,20-22: «dejando las redes, dejando la barca y a su padre... le siguieron»; Lc 5.27ᄀ28: «Leví... dejándolo todo, se levantó y lo siguió»; sólo así se entra en el reino (Mc 10,23-24).

La radicalidad de la exigencia de seguir a Jesús se acentúa hasta el límite donde en el texto de Lucas encontramos: «si alguno viene donde mí y no odia a su padre..., y hasta su propia vida, no puede ser discípulo mío». Comentando este hecho Galindo 
(1988) nos dice que el verbo «odiar» expresa aquí, según el uso semítico, la indiferencia frente a los parientes y la adhesión absoluta a Jesús. Con todo, se debe tener en cuenta que para el seguimiento se una exclusividad en el seguimiento tal que implica, llegado el caso, renunciar a los lazos familiares más íntimos y «hasta la propia vida». Dicho de otro modo: la opción por Jesús puede comportar la ruptura de los vínculos de sangre, si éstos se interponen en el seguimiento exigido.

Así podemos constatar que la entrada en el reino ha de ir precedida por un proceso articulado en tres fases sucesivas: llamamiento, despojamiento, seguimiento. Nadie tiene acceso al reino sin seguir a Jesús; nadie puede seguir a Jesús sin haber sido llamado; la llamada despoja al discípulo haciéndolo enteramente disponible y le habilita para «tomar la cruz». Este proceso se realiza porque Jesús mismo hará ese camino y que debe enseñar a los suyos.

Con todos estos hechos y dichos, Jesús crea una comunidad de gente dispuesta a compartir con él su vida y su destino. En ella se manifiesta, si bien de forma todavía incipiente -como un grano de mostaza-, la grandeza incomparable del reino. Sus miembros se adhieren a Jesús con una confianza tal que los hace capaces de superar cualquier dificultad; la opción por el reino supone una ruptura con los vínculos personales y los modos de existencia previos. Únicamente quien renuncia del todo a todo es digno de Jesús. Pero tal renuncia, a primera vista tan costosa, se revela de inmediato como el hallazgo del «tesoro escondido» $\mathrm{y}$ de «la perla fina» (Mt 13,44-46), con los que ningún otro valor puede compararse ventajosamente.

\subsection{El Dios de Jesús es «Abba»}

Debemos hacer notar que en el Antiguo Testamento sólo muy raramente se le atribuye a Dios el título de padre. Sin embargo, es ese título el que Jesús emplea, y por cierto con el término familiar Abba, para dirigirse a aquél cuyo reino proclama. Tal uso aparece no sólo en los textos comunes a la tradición sinóptica (fuente $\mathrm{Q}$ ), sino también en tradiciones propias de Mt y Lc: Mc 14,36; Mt 11,26; Lc 23,34-46.

Jesús enseña a sus discípulos este modo de nombrar a Dios, de manera muy peculiar y familiar e incluso trasmite a «la gente» esta enseñanza. Dios, según Jesús, es Padre y como tal debe ser invocado, por encima de cualquier otro título.

Ahora bien teniendo en cuenta la relación entre Dios y el hombre, la actitud del hombre ante Dios ha de ser la del niño ante su padre: «si no cambiáis y os hacéis como los niños, no entraréis en el reino de los cielos» (Mt 18.3). Pero ¿En qué consiste este «hacerse como los niños»? podemos afirmar que el niño encarna la pureza y la pequeñez humilde, pero sobre todo es el prototipo del desvalimiento, de la necesidad absoluta del padre para sobrevivir. Por tanto, lo que Jesús trata de inculcar en sus oyentes podría parafrasearse de esta manera: «si no aprenden a estar ante Dios como el niño pequeño ante su abbá, no entrarán en el reino». El comienzo de la salvación tiene como un primer escalón, aprender a llamar a Dios «padre querido».

La paternidad de Dios se pone a prueba y se acredita en su impresionante autenticidad sobre todo frente al pecado del hombre. Tan de verdad es Dios padre para el hombre que sólo por su amor paternal se explica su forma de proceder 
con él. Las tres parábolas del perdón de Lc 15 son, en realidad, otras tantas parábolas de la predilección divina por los pecadores. Su común denominador es: Dios ama más a los menos dignos de ser amados porque son los más necesitados de su amor. Los más amados son los menos amables a los ojos del mundo porque Dios ama, como crea, desde la nada.

Jesús no se ha limitado a proclamar la paternidad misericordiosa de Dios, sino que ha ajustado su conducta a esta proclamación. A las palabras se suman las acciones; a la teoría, la práctica. La predilección por los pecadores se ratifica en el gesto de comer con ellos; el alcance simbólico del mismo -la comunión de mesa equivalía a una comunión de vida y de destino, lo que provocó a menudo el escándalo de los maestros de la ley.

Junto con la predilección por los pecadores, Jesús manifestó repetidamente su predilección por «los pequeños»; esta designación comprende la vasta gama de seres humanos marginales. Los pobres, los enfermos, las mujeres, los niños, son los preferidos de Jesús. Las bienaventuranzas y la parábola del rico Epulón son taxativas al respecto, como lo son los textos de Mt 25, 40-45 («lo que hicisteis a uno de estos hermanos míos más pequeños, a mí me lo hicisteis»), Mt 11,25 (Jesús da gracias al Padre por revelar a «los pequeños» lo que oculta a los sabios). Mc 9.42 (quien escandaliza a «los pequeños» se condena), etc. En todos estos textos «los (más) pequeños» son la viva encarnación de aquel grano de mostaza («la más pequeña de las semillas») con que se había simbolizado el comienzo del reino. La razón de esta preferencia por los más débiles y pecadores es clara puesto que Jesús habla y actúa así porque así piensa y obra Dios. La gratuidad de la voluntad salvífica del Padre conlleva la primacía absoluta de los desprovistos de títulos y méritos. De esta forma, Jesús realiza una operación de recuperación de lo humano desde abajo, comenzando por los últimos y convirtiéndolos en primeros (Mt 19,30). El ser humano más insignificante, justamente en cuanto insignificante según la común estimación, es el valor más alto de la realidad en la peculiar valoración que Jesús hace del conjunto de las criaturas. «Uno solo de estos pequeños» vale más que todo.

En consecuencia el Dios que reina ahora es el Padre que ama y perdona, que prefiere a los pequeños «porque es bueno», ante quien el hombre ha de sentirse hijo y no siervo. El reino de Dios se desvela entonces como el reino del hombre, en el que los pecadores son preferidos, los más pequeños son los más grandes y los últimos son los primeros. No es el reino del poder y la fuerza, sino de la gracia y la debilidad. Jesús llama al seguimiento con vistas a la instauración de ese reino, o lo que es lo mismo, con el objeto de crear una comunidad nueva, distinta a lo que se pretendía desde los grupos existentes en la región (Zelotas, fariseos, esoterismo, etc.). El rasgo distintivo de esa comunidad, con la que amanece el verdadero reino, es la invocación de Dios como Abbá, el reconocimiento de la propia filiación y el establecimiento de la fraternidad interhumana (Jeremías: 1992).

\section{La doctrina paulina de la Gracia}

Pablo es el expositor por excelencia de la doctrina bíblica de la Gracia. A él se debe la formulación del término cháris con el sentido técnico que luego se hará común en el uso teológico.

Dicho término, que no aparece en los evangelios sinópticos es empleado 
permanentemente por Pablo, que hace el tema central de su comprensión de la fe cristiana sin descuidar el otro tema que es la justificación.

\subsection{La Gracia}

Ya en sus primeros escritos, y probablemente bajo el recuerdo imborrable de su experiencia de Damasco, Pablo reflexiona acerca del misterio de la vocación cristiana. En continuidad con las ideas del Antiguo testamento, afirma por de pronto que los creyentes lo son porque han sido objeto de una elección («conocemos, hermanos,...vuestra elección»: ITs 1,4; «Dios os ha elegido desde el principio»: 2 Ts 2,13 ) o de una llamada ( $(, .$. os ha llamado»: 2 Ts 2;14; «..,aquellos que han sido llamados»): Rm 8,28), que es (gracia de nuestro Dios) (2 Ts 1, 12; cf. 1 Co 3.10: $15,10)$, su «don del consuelo eterno» Ts $1,12)$; y no mérito del hombre, que «no debe atribuirse cosa alguna» (2 Co 3,5), puesto que es «recipiente de barro» que pone en evidencia «la fuerza divina, y no humana» (2 Co 4,7; cf. 12,10).

Esta idea de una elección por voluntad y libertad absoluta de Dios, por gracia, no abandonará ya a Pablo todo lo contrario continuamente regresa a dichos conceptos y los hace presente en sus cartas. El «resto de Israel» subsiste porque «ha sido elegido por gracia» (Rm. $11,6)$ y la gracia es «don de Dios».

La introducción a la carta de los Efesios es un himno a este llamado por pura Gracia y, por la que Dios dispone santificar y glorificar en Cristo a «los elegidos de antemano según el previo designio» (Ef 1,11), llamado que debe suscitar no tanto sentimientos de temor o angustia cuanto la certeza gozosa de haber sido alcanzados por la benevolencia divina, «que realiza todo conforme a la decisión de su voluntad» (Ef 1,11 b).

Estas ideas difícilmente habrían podido surgir en la mente de Pablo sin la herencia del Antiguo testamento, de un Dios compasivo y misericordioso. Sólo que el apóstol cuenta ahora con un dato adicional para corroborar esa imagen divina: el hecho de que Dios «no se reservó ni a su propio Hijo, antes bien le entregó por todos nosotros», lo que le permite «estar seguro» que nada ni nadie «podrá separarnos del amor de Dios manifestado en Cristo» (Rm 8,31-39).

Con estos antecedentes, el término cháris sirve a Pablo para designar la condensación de todos los gestos y etapas de la iniciativa salvífica divina, más su saldo resultante. De ahí que lo use al comienzo y al final de muchas de sus cartas (1 Co 1,3; 16,23; 2 Co 1,2; 13,13; Ga 1. 3; 6,18; Ef 1,2; 6,24; Flp 1,2; 4,23; Col 1,2; 4,18), no como mera fórmula establecida de saludo y despedida, sino a modo de inclusión, como cifra compendiada del entero mensaje de sus cartas.

Este sentido englobante de cháris aparece nítidamente en Rm 3.23-24: «todos pecaron y están privados de la gloria de Dios y son justificados por el don de su gracia en virtud de la redención realizada en Cristo». Todos los elementos del acontecimiento salvífico se dan cita aquí:

a. La previa pecaminosidad universal;

b. La redención del pecado por parte de Cristo, que otorga la justificación;

c. El don de la gracia divina, que hace inteligible el tránsito sorprendente e inesperado de las dos propuestas anteriores.

Esta Gracia (cháris) conferida gratuitamente es más efectiva y radical 
que la sola compasión y misericordia divinas a las que apelaba el Antiguo Testamento; es el poder escatológico que aniquila el pecado del mundo para poner en su lugar la salvación universal. La gratuidad de esta salvación, puesta aquí de relieve por el empleo redundante de dos términos: «la Gracia y el don en Gracia».

El sentido totalizante que Pablo otorga a cháris se comprende mejor si se advierte que para él los contenidos concretos del término se identifican, en última instancia, con la persona de Cristo. La cháris paulina no es algo, sino alguien. Según Pablo, no basta con decir que hemos obtenido el acceso a ella por Cristo; hay que decir además que el don es Cristo mismo: él es, en efecto, lo que nos ha sido dado graciosamente (Rm 8,32). La salvación por gracia consiste en un ser vivificado y resucitado con Cristo; el don gratuito de Dios es la vida en Cristo. Dicho brevemente: la Gracia de Dios, es la Gracia de Cristo y la Gracia de Cristo, es Cristo mismo.

Esta concentración cristológica del concepto de gracia, que había sido anticipada en los sinópticos con su concepción del seguimiento de Jesús, es el rasgo que marca más netamente las distancias entre los dos Testamentos con respecto a la gracia.

También es importante destacar que Pablo asocia frecuentemente la idea de gracia a la de liberación. Él es el único autor del Nuevo testamento que utiliza sistemáticamente el vocabulario derivado del sustantivo «libertad». No se trata aquí tanto del libre albedrío cuanto de la liberación del estado de Alienación descrito en Rm 7,14ss., que ha caducado con el don escatológico de la gracia. Y así, la vida que nos ha sido dada en Cristo «libera de la ley del pecado y de la muerte» no sólo a los humanos, sino a la entera creación (Rm. 8,2.21.23); el agraciado ya no es esclavo, sino hijo» (Ga 4,7); «Cristo nos libertó para la libertad»; la vocación cristiana es, por tanto, un «ser llamado a la libertad) (Ga 5,1.13; cf. 1 Co 7,22: «el que recibió la llamada del Señor siendo esclavo, es un liberto del Señor»); la verdadera libertad está «allí donde está el Espíritu del Señor) (2 Co $3,17)$.

Esta doctrina de la libertad en y por Cristo tenía que resultar singularmente significativa en un mundo como el helenista, angustiado por el sentimiento trágico de una fatalidad inexorable, agobiado por el peso de las potestades cósmicas o las divinidades caprichosas y despóticas (cf. Ga 4,3.8-11; Col 2,8). Pero servía también para desatar las múltiples ataduras que imponía a las conciencias el legalismo judaico, con su proliferación de normas, vetos y tabúes (Ga 5,1-6; Col 2.16-23) (Auer: 1975).

La doctrina paulina de la gracia como don liberador no podía menos de suscitar fuertes oposiciones entre ciertos grupos de cristianos procedentes del judaísmo, que no parecían haber comprendido aun cabalmente el significado escatológico del acontecimiento Cristo. Frente a ellos Pablo va a hacer valer el razonamiento de la justificación por la fe, más no por las obras de la ley.

\subsection{La Justificación en la Carta a los Romanos}

Al comentar sobre el tema de la Justificación en la carta a los romanos, Ruiz de la Peña (1991) dice que el contexto que se presenta en la carta a los romanos sigue siendo el mismo que se presenta en la carta a los gálatas: la necesidad de atajar las desviaciones 
judaizantes en torno al concepto clave de justificación. Contra una economía de salvación fundada en los principios del mérito y la retribución, cuyo instrumento serían las obras de la ley. Pablo diseña una economía de salvación fundada en el principio del amor gratuito divino, cuyo instrumento es la fe y de esta manera se presenta:

a. A la alianza del Sinaí, entendida como contrato (cuasi) bilateral, se opone la promesa hecha con anterioridad a cualquier prestación humana o lo que es equivalente: a Moisés se opone Abraham, quien «no obtuvo la justicia por las obras», sino porque «creyó en Dios» y esa fe «le fue la estima como justicia» en virtud de la promesa divina de la que «se fió enteramente». Abraham era el prototipo del Justo en el Antiguo Testamento; Pablo aprovecha esta apreciación para hacer ver que aquello por lo que agradó a Dios no consistía en ningún tipo de obras, sino en la fe, es decir, en la adhesión sin vacilaciones a la palabra de la promesa que se le había dirigido.

b. A los méritos de los patriarcas se opone la elección y llamada anteriores e independientes de cualquier mérito. En Gal 1,15 Pablo mencionaba su propio caso como ilustración de este modo divino de proceder: a él Dios «lo separó desde el seno de su madre y lo llamó por su gracia». Pues bien, así es como actúa Dios en todos los casos, interviniendo «para bien... de aquéllos que han sido llamados... A los que de antemano conoció, también los predestinó ... A los que predestinó, a ésos también los justificó; a los que justificó, a ésos también los glorificó» (Rm 8.28-30; cf. 9. 11-13.20-24). c. A la justificación fundada en una presunta justicia distributiva divina se opone la justificación fundada en la justicia salvífica gratuita: «pero ahora, independientemente de la ley, la justicia de Dios se ha manifestado»; tal manifestación es un escalón en que, si bien «todos pecaron» (y, por tanto, nada podían merecer de una justicia distributiva), los pecadores «son justificados por el don de su gracia»; así es cómo Dios «muestra su justicia en el tiempo presente, para ser el justo y justificador» (Rm 3,21-26). El ahora mencionado en el v. 21 es el kairós escatológico del v.26, momento privilegiado de la historia en el que se revela que Dios es justo por el hecho de que es justificado (Jeremías: 1992)

d. En fin, a la justificación por las obras de la ley se opone la justificación por la fe. Pablo repite el razonamiento de Gal 2,1 presentándolo con diversas formulaciones, a modo de variaciones sobre el mismo tema: la justicia de Dios se ha manifestado «independientemente de la ley... por la fe en Jesucristo» (Rom. 3,21); en 3,27 se contraponen «la ley de las obras» y «la ley de la fe»; en 3,28 se asevera enfáticamente que «el hombre es justificado por la fe, sin las obras de la ley».

Somos justificados por la fe; ha señalado siempre en el discurso que hace siempre Pablo y entiende por esta confianza, al menos y en principio, una adhesión personal del cristiano a Cristo. En este sentido, la fe paulina es el acto más libre (más humano), puesto que se trata del establecimiento de relaciones interpersonales, y a la vez más manifestativo de la radical insuficiencia humana para obtener autónomamente la propia salvación, puesto que con 
él el creyente reconoce expresamente la necesidad absoluta de Cristo y se entrega enteramente a él, en respuesta a la total auto entrega con que Cristo lo ha gratificado.

Así pues, la fe comporta ante todo una decisión; el hombre que recibe la llamada de Dios ha de optar. Tal opción entraña el compromiso de la conversión, del cambio de vida; Pablo expresa esta idea hablando de la fe como «obediencia», correlativamente, de la incredulidad como «desobediencia» o «rebeldía». Pero la obediencia no servil, sino humana, sólo puede darse allí donde hay confianza. De modo que creer es obedecer y obedecer es entregarse confiadamente a la voluntad de quien merece crédito. La fe arquetípica, la de Abraham, fue una obediencia que nacía de la confianza, del «esperar contra toda esperanza): (Rm 4,18).

Designando la fe como obediencia, Pablo está además apuntando a otro de los aspectos de su concepción de la pístis (confianza); su dimensión objetiva. La fe dice, en efecto, relación esencial a la revelación de Dios al hombre, que alcanza su punto culminante en el acontecimiento Cristo y en su evangelio. Creer, pues, significa tener por verdadero algo, reconocer y aceptar la palabra revelada. Pablo ansía llevar el evangelio a los romanos porque es «fuerza de salvación para el que cree en él», «porque en él se revela la justicia de Dios) (Rm 1. 15-17): el apóstol manda de una «confesión de boca» a la fórmula de fe que ha de ser creída en el corazón y que comprende hechos cuya veracidad hay que aceptar (Rm 10.9-10). De ahí que la predicación sea condición indispensable de la fe: ¿cómo invocarán a aquel en quien no han creído? ¿Cómo creerán en aquel a quien no han oído? ¿Cómo oirán sin que se les predique?... Por tanto, la fe viene de la predicación» (Rm. 10,14-17; cf. 1 Co 3,5; I5, 1-3.1 1). La fe es, respuesta a una propuesta, aceptación de un mensaje, creer en alguien, fiarse de él por entero, importa creer a ese alguien, dar crédito a lo que nos comunica; ambos momentos son inseparables. Como es obvio. Pablo no los distingue expresamente, pero su comprensión de la fe sería mal entendida si sólo se retuviera uno de ellos dejando de lado el otro.

Por último, la contraposición .fe obras, ¿es una desautorización expresa de toda obra? Rm 2.10 13 impone de entrada una cierta cautela, a la hora de responder a esta pregunta: «gloria, honor y paz a todo el que obre bien; al judío y al griego... Que no son justos ante Dios los que oyen la ley, sino los que la cumplen; esos serán justificados (cf. 2.26). El texto parece dar por bueno el principio retributivo de la recompensa a las obras «en Dios no hay acepción de personas», por lo que «dará a cada cual según sus obras) $(2,6.10)$.

Por lo demás, «si eliminásemos de los escritos paulinos las exhortaciones éticas (la importancia de las obras), nos quedaríamos con menos de la mitad». ¿Qué pensar entonces del valor del recto obrar en la mente de Pablo?

Para salir del impase hay que tener presente que, según el apóstol, la fe que justifica es la que va unida al amor - y a sus obras. «En Cristo Jesús ni la circuncisión ni la incircuncisión tienen valor, sino solamente la fe que actúa por la caridad» (Gal 5,6; cf. 5,13-14); «con nadie tengáis otra deuda que la del mutuo amor. Pues el que ama a su prójimo ha cumplido la ley... La caridad es, por tanto la ley en su plenitud.

Así pues, la contraposición fe - obras, lejos de significar una descalificación 
del recto obrar -lo que conduciría a la anomía ética quiere tan sólo ser una impugnación de la autocomplacencia típicamente judaica en el propio mérito, tan gráficamente denunciada ya en la parábola del fariseo y el publicano.

Con todo, la propuesta de la justificación por la fe, no por las obras, debió de crear problemas en las primeras comunidades, pues se prestaba fácilmente a falsas interpretaciones. El texto de Gal 5,13 parece insinuar que tales malentendidos pudieron darse ya en las propias comunidades paulinas. En todo caso, las llamativas formulaciones de St 2,14-26, que invierten literalmente el razonamiento paulino, demuestran que hubo efectivamente dificultades en otras comunidades, y que tuvieron que ser clarificadas con enunciados y razonamientos como los del apóstol.

De este modo: gracia, justificación, fe son tres conceptos fundamentales del pensamiento sobre la salvación de Pablo. Cada uno de ellos implica a los otros dos y lo que resulta de esta tríada inseparable es un nuevo modo de ser, «ser en Cristo»; expresión que Pablo no se cansa de repetir y que denota un cambio radical de la condición humana, tanto en el nivel ontológico como en el operativo. «El que es en Cristo, es nueva creación; pasó lo viejo, todo es nuevo» (2 Co 5,17); en la raíz de esta mutación está el hecho ya apuntado de que la Gracia de la justificación por la fe consiste en un vivir Cristo en nosotros: el ser en Cristo equivale en realidad al ser Cristo en nosotros. La justificación produce la unión interpersonal, la comunión vital entre Cristo y el cristiano.

\section{CONCLUSIÓN:}

Habiendo realizado un camino en la comprensión de la Gracia de manera sintética primero desde el Antiguo Testamento y luego desde el nuevo testamento y como modo de conclusión podemos afirmar lo siguiente:

- Desde el principio Dios tiene un plan-proyecto sobre el hombre y el mundo y que la Biblia lo expresa desde los términos de una Alianza, un pacto que quiere entrar en diálogo y por ello crea seres capaces de entrar en diálogo con Él y los invita a una alianza de amistad y de filiación.

- En el Antiguo Testamento no se presenta de manera explícita la palabra Gracia, sin embargo ya existe una comprensión en esa línea, puesto que ya se tiene conciencia de ser pueblo de Dios y de la elección hecha de manera gratuita, a través de una alianza irrompible y del amor entrañable y misericordioso.

- También podemos descubrir que los hebreos experimentan esta realidad como una actitud benevolente de Dios que los ha escogido y los ha acompañado a lo largo de toda su historia y esta elección gratuita (Gracia) se identifica con la historia de la Alianza que se materializa en una paz política, un bienestar social, de liberación, etc. de tal modo que la gracia no es un medio para llegar a la salvación, sino que equivale a la salvación misma que Dios otorga al hombre gratuitamente.

- En el Nuevo Testamento la gracia se presenta como el acontecimiento definitivo de salvación. Dios es quien salva al hombre de su perdición, por la obra de Cristo; este acontecimiento se expresa en diversas formas como rehabilitación del culpable, santificación del hombre, vida, luz, participación de la naturaleza divina. 
- La Gracia es fundamentalmente un favor, benevolencia y beneficio de Dios, esto es que es el mismo Dios que se dirige al hombre con amorosa misericordia, para darle no sólo lo que es suyo, sino darse a sí mismo, para ofrecerle su amistad.

- En los evangelios sinópticos se presentan el reino de los cielos y el llamamiento a seguir a Jesús como pura gracia e iniciativa de Dios Padre que ama y perdona y que prefiere a los más pequeños, donde el hombre se siente hijo y no siervo, por ello es libre ante la oferta de la gracia, pero tiene que asumir con responsabilidad lo que ella contiene, pero al mismo tiempo puede rechazar también con igual responsabilidad.

- San Pablo es quien utiliza de manera frecuente y explícita el término Gracia (cháris), que es conferida gratuitamente, esta gracia no es algo sino es un alguien: Cristo mismo que se nos ha dado de manera gratuita, que nos salva y nos resucita, por ello repite San Pablo: "el don gratuito de Dios es la vida de Cristo, es la gracia de Dios, es la gracia de Cristo y la gracia de Cristo es Cristo mismo que se nos entrega".

- Pablo presenta de manera fundamental otro concepto que es la justificación, es la acción salvadora de Dios en el hombre, puesto que, dice pablo, la fe nos justifica, es decir, nos hace justos, nos perdona, nos libera, cambiando nuestra condición, sin embargo también Pablo nos refiere que si bien la justificación es obra de Dios no elimina la libertad del hombre, tampoco se pierde el sentido de las obras puesto que las obras del amor demuestran la existencia de la fe.

- Por otrolado podemos descubrir queel mayor obstáculo que puede encontrar la Gracia es la autosuficiencia humana, donde considera que no necesita de nada ni de nadie, no requiere de ese ser trascendente y cercano que quiere entrar a compartir nuestra vida y llevarnos a la salvación donde libremente debemos optar.

\section{REFERENCIAS:}

AUER, J. (1975). El evangelio de la Gracia. Barcelona: Editorial Herder.

GASTALDI, I. (1994) El hombre un misterio: Aproximaciones filosóficoteológicas. Buenos Aires: Ediciones Don Bosco.

GALINDO, J. A. (1998) Compendio de la Gracia. Valencia: Edicep.

JEREMÍAS, J. (1979) Las parábolas de Jesús. Navarra. Editorial Verbo Divino.

JEREMÍAS, J. (1985) Interpretación de las parábolas. Navarra: Editorial Verbo Divino.

JEREMIAS, J. (1992) Abba y el mensaje central del Nuevo Testamento. Salamanca: Sígueme

LOHSE, E. (1985) Introducción al Nuevo Testamento. Madrid: Ediciones Cristiandad.

LONA, H. (1998) Escatología y Gracia del Nuevo Testamento: aporía y desafío. Asunción: Editorial Don Bosco.

MEJÍA, J. (1975) Introducción al Antiguo Testamento: Amor, pecado, alianza. Buenos Aires: Editorial Patria Grande.

RUIZ DE LA PEÑA, J. (1991) Don de Dios: Antropología teológica. Santander: Sal Terrae. 